\title{
Urodynamic Features of the Voiding Dysfunction in HTLV-1 Infected Individuals
}

\author{
Neviton M. Castro, Daniel M. Freitas, Waldyr Rodrigues Jr., Andre Muniz, Paulo Oliveira, \\ Edgar M. Carvalho
}

Section of Immunology, University Hospital, Bahia Federal University, Salvador, Bahia, Brazil

\begin{abstract}
Objective: To describe urodynamic abnormalities in HTLV-1 infected individuals presenting urinary symptoms and verify if these findings and quality of life (QOL) evaluation correlate with overall neurological impairment.

Materials and Methods: From January/2001 to May/2004, 324 HTLV-1 seropositive subjects were evaluated to determine the occurrence of urinary symptoms. Urodynamic testing was performed in those who complained of frequency, urgency, or incontinence. They went through a complete clinical, neurological, and urological examination to investigate symptoms and signs of myelopathy. Neurological disability was assessed by Expanded Disability Status Scale (EDSS).

Results: From the 324 patients evaluated, 78 underwent the urodynamic testing. Fifty-seven individuals were females $(73.1 \%)$ and age ranged from 23 to 76 years (mean $=48.7$ years; $\mathrm{SD} \pm 11.6$ ). Urodynamic testing was abnormal in 63 patients $(80.8 \%)$. The major abnormality was detrusor overactivity (DO), observed in 33 individuals $(33 / 63 ; 52.4 \%)$, followed by detrusor-external sphincter dyssynergia (DESD), diagnosed in 15 subjects $(15 / 63 ; 25.4 \%)$. HAM/TSP patients had significantly more DESD than the HTLV-I carriers ( $\mathrm{p}=0.005$; OR $=5.5$; CI: 1.6 to 19.4). QOL was severely compromised in HAM/ TSP patients.

Conclusions: Prominent urodynamic abnormalities were identified in individuals genuinely considered as HTLV-I carriers, suggesting an early compromise of the urinary tract; whereas HAM/TSP patients presented urodynamic findings, which posed a potential risk to the upper urinary tract (dyssynergia). Urodynamic evaluation should be performed in all HTLV-Iinfected individuals with voiding complaints.
\end{abstract}

Key words: human T-lymphotropic virus 1; paraparesis, tropical spastic; urinary tract; urinary bladder, neurogenic Int Braz J Urol. 2007; 33: 238-45

\section{INTRODUCTION}

Human T-cell lymphotropic virus type I (HTLV-1) is a retrovirus that infects about 10 to 20 million people worldwide with endemic foci in Southern Japan, the Caribbean, Central and South Africa, and South America (1). In Brazil, this viral infection is endemic, being Salvador, Bahia state, the city with the highest prevalence (1.35\%) among blood donors (2). The HTLV-1 transmission occurs through blood transfusions, sexual intercourse, contaminated needles, or breast-feeding. About 5\% of HTLV-I infected individuals develop either adult T-cell leukemia (ATL) or a chronic inflammatory disease of the central nervous system.

The association between HTLV-I infection and tropical spastic paraparesis was first made in 1985 (3). An independent work in Japan also found an 
association between HTLV-I and myelopathy in 1986 (4). In 1989 the World Health Organization designated the term HTLV-I-Associated Myelopathy/Tropical Spastic Paraparesis (HAM/TSP) for the neurological syndrome associated to this virus. HAM/TSP is a chronic and slowly progressive inflammatory myelopathy that may lead to severe neurological disability (5).

The neurological presentation begins insidiously after a variable latency period. The first complaints are generally related to the gait and are associated to a functional asymmetric crural limitation, weakness, rigidity and sensitivity loss in the lower limbs, as well as low back pain. There can also occur urinary and intestinal disturbs and erectile dysfunction $(6,7)$.

Urologic manifestations are present in up to $90 \%$ of HAM/TSP patients and are characterized by: frequency, urgency, and urge-incontinence (8-10). In a recent large series of HTLV-I infected individuals the urinary symptoms were closely related to the neurological disability measured by the Expanded Disability Status Scale (EDSS) (11). They have an insidious onset and may occur as an isolated manifestation of the myelopathy, allowing early intervention for the disease (12). Urodynamic evaluation allows the assessment of both detrusor and external sphincter functions and its findings may be extrapolated to identify the region of the neurological compromise (13). Such testing is generally indicated in patients with moderate to severe incontinence, those suspected of having neurological disease, and those with urge-incontinence when infection and neoplasm have been excluded. Obstructive problems may also need urodynamic evaluation for diagnosis and management decision (14).

The purpose of this study was to evaluate and describe the urodynamic abnormalities in HTLV-I infected individuals from a multidisciplinary HTLV-I outpatient department and verify if these findings and quality of life (QOL) evaluation correlate with the overall neurological impairment.

\section{MATERIALS AND METHODS}

From January 2001 to April 2005, 324 HTLVI infected individuals were evaluated at the multidisciplinary HTLV-I outpatient department at the University Hospital of the Bahia Federal University. The HTLV-I positive individuals were referred from blood banks after a positive screening or from other neurological services throughout the state. In all cases the diagnosis of HTLV infection was established by ELISA(Cambridge Biotech Corp., Worcester, MA, USA) and confirmed by Western blot analysis, differentiating HTLV-I from HTLV-II (HTLV blot 2.4, Genelab, Singapore).The HTLV-I positive individuals were then evaluated by several specialists in an ordered and consecutive fashion. They went through a complete clinical, neurological and urological evaluation.

Neurological disability was determined based upon Expanded Disability Status Scale (EDSS) (11) by the assisting neurologist (A.M.). This scale is a good predictor of disease severity in Multiple Sclerosis (MS) for it evaluates the compromise of multiple systems, such as pyramidal, sensory, bladder, bowel, visual, cerebellar, and mental functions. Owing to similarities in the pathogenesis and clinical picture of MS and HAM/TSP, this scale has been widely used to evaluate disease severity in HAM/TSP patients. It ranges from 0 (normal) to 10 (death due to HAM/ TSP). HTLV-I-associated myelopathy was clinically defined as EDSS $\geq 3$. Patients were divided into 2 groups: HTLV-I carriers (group 1), composed of individuals who did not fulfill the criteria for HTLV-I-associated myelopathy (EDSS < 3), and HAM/TSP patients (group 2) who had EDSS $\geq 3$.

These subjects were also assessed by the assisting urologist (N.C.) using a semi-structured anamnesis, complete overall and urogenital physical examination, a standardized questionnaire (Urinary Distress Inventory - UDI) to determine the occurrence of urinary complaints (15) as well as a quality of life (QOL) questionnaire (Ditrovie) (16). Individuals presenting urinary symptoms went through urinalysis and urine culture. Those who presented urinary infection were treated before enrollment in the study. Urinary tract ultrasonography was also used as complementary exam. It is the preferred method to evaluate the upper urinary tract of patients presenting neurological origin urinary disturbs (17).

In this study, patients of both genders, untreated, 18 years of age or older, presenting urinary 
symptoms (urgency, incontinence, nocturia, an increased urinary frequency, sensation of postmiccional residue, and dysuria) were referred for urodynamic evaluation at specialized clinics in order to obtain further information on the degree of bladder dysfunction. The urodynamic testing is a broadly used method for investigation of vesical dysfunctions. The urodynamic evaluation included uroflow analysis, miccional residue measurement, cystometrogram, electromyography, abdominal pressure, differential pressure, pressure-flow testing, and vesical sensitivity.

Individuals who had other neurological diseases, or psychiatric disorders; pregnant women; patients taking any kind of medicine that acts in the central nervous system (CNS) or that interferes with normal urinary tract function; as well as those who did not sign the informed consent or did not follow the protocol were excluded from the study.

This study was submitted to and approved by the Ethics Committee of University Hospital, UFBA.

Collected data were inserted in a data bank and analyzed with the help of two statistical packages (SPSS version 11.5 and GraphPad Prism version 3.0). The Pearson Chi-Square and Fisher's Exact Test were used to verify univariate differences between the groups.

\section{RESULTS}

From the 324 HTLV-I seropositive individuals, $51.9 \%$ were males with ages ranging from 18 to
82 years (mean $=43.2$ years of age; $\mathrm{SD} \pm 13.4$ years). One hundred and sixty-one individuals (49.7\%) presented urinary complaints as assessed by UDI. From these, 85 subjects had urodynamic test available; however, urodynamic testing results and neurological evaluation (as assessed by EDSS) were available in 78 subjects and these were enrolled in the analysis of this study. From the 78 subjects, 57 were females $(73.1 \%)$ and age ranged from 23 to 76 years (mean = 48.7 years; $\mathrm{SD} \pm 11.6$ ). The subjects' classification according to EDSS, as well as the group division and mean age \pm SD can be seen in Table-1. Individuals in group 2 were older than those in group 1 (groups $1 \mathrm{x}$ 2: Mann-Whitney U Test, $\mathrm{p}=0.02$ ).

In the studied group, frequency was the most commonly reported symptom. It was the complaint of 58 subjects $(74.4 \%) ; 49$ patients $(62.8 \%)$ referred presenting urgency; incomplete bladder emptying was the complaint of 45 individuals (57.7\%); 40 HTLV-I infected individuals (51.3\%) complained of frequency; abdominal straining was referred by 23 subjects (29.5\%) as well as dysuria. Seven subjects (3 HTLVI carriers and 4 HAM/TSP patients) presented all six urinary symptoms.

The urodynamic testing was abnormal in 63 patients $(80.8 \%)$. The major abnormality was detrusor overactivity (DO), which was observed, in 33 individuals $(33 / 63 ; 52.4 \%)$, followed by detrusor-external sphincter dyssynergia (DESD), diagnosed in 15 subjects $(15 / 63 ; 25.4 \%)$. The urodynamic testing was inconclusive in 1 case, an HTLV-I carrier who com-

Table 1 - Characteristics of HTLV-I carriers and HAM/TSP patients.

\begin{tabular}{|c|c|c|c|c|}
\hline \multicolumn{2}{|c|}{ Characteristics } & \multirow{2}{*}{$\begin{array}{c}\text { HTLV-I Carriers } \\
(\mathrm{n}=45)\end{array}$} & \multirow{2}{*}{$\begin{array}{c}\text { HAM/TSP } \\
(\mathrm{n}=31)\end{array}$} & \multirow{2}{*}{$\begin{array}{c}\text { p Value } \\
0.015^{*}\end{array}$} \\
\hline Age & Mean \pm SD & & & \\
\hline Gender & $\begin{array}{l}\text { Male }(\mathrm{n}-\%) \\
\text { Female }(\mathrm{n}-\%)\end{array}$ & $\begin{array}{l}12-26.1 \% \\
34-73.9 \%\end{array}$ & $\begin{array}{r}9-28.1 \% \\
23-71.9 \%\end{array}$ & $0.84^{+}$ \\
\hline Skin color & $\begin{array}{l}\text { Black (n-\%) } \\
\text { Non Black (n-\%) }\end{array}$ & $\begin{array}{l}15-34.9 \% \\
28-65.1 \%\end{array}$ & $\begin{array}{r}6-23.1 \% \\
20-76.9 \%\end{array}$ & $0.30^{+}$ \\
\hline
\end{tabular}

HAM/TSP $=$ HTLV-I-Associated Myelopathy /Tropical Spastic Paraparesis; $*=$ Student t test $;{ }^{+}=\chi^{2}$. 
plained of nocturia and sensation of incomplete bladder emptying. The urodynamic findings according to EDSS are depicted in Figure-1.

HTLV-I associated myelopathy patients had significantly more DESD than the HTLV-I carriers $(\mathrm{p}=0.005 ; \mathrm{OR}=5.5 ; \mathrm{CI}: 1.6$ to 19.4). No difference was observed regarding the frequency of DO $(\mathrm{p}=$ 0.49) in HAM/TSP patients and HTLV-I carriers. The frequency of the urinary complaints in HTLV-I infected individuals who presented either DO or DESD on urodynamic evaluation is shown in Table2.

\section{COMMENTS}

The urodynamic evaluation is of great importance in characterizing the functional disturbances of the bladder. The urodynamic test is a key element to assess the incontinence type in order to establish the appropriate treatment. This evaluation allows us to graduate the urological compromise and to correlate it with myelopathy severity. The present study describes the urodynamic findings in HTLV-I-positive individuals, according to EDSS classification and urinary symptoms. Although HAM/TSP is a well documented complication of HTLV-I infection, few studies specifically described the associated urological problems.

In HAM/TSP there is a slow and progressive degeneration of the lateral funiculus of the spinal cord, involving the lateral cortico-spinal tract as well as the descending autonomic fibers from the hypothalamus, spinocerebellar and spinothalamic tracts of the lateral column, especially at the thoracic level (18).

Urodynamic evaluation should be performed in all HTLV-I-infected individuals with voiding complaints. The majority of HAM/TSP patients with voiding dysfunction had irritative symptoms associated with detrusor overactivity on cystometric evaluation consistent with a disruption of the pontine reflex pathways. This result is consistent with previous studies

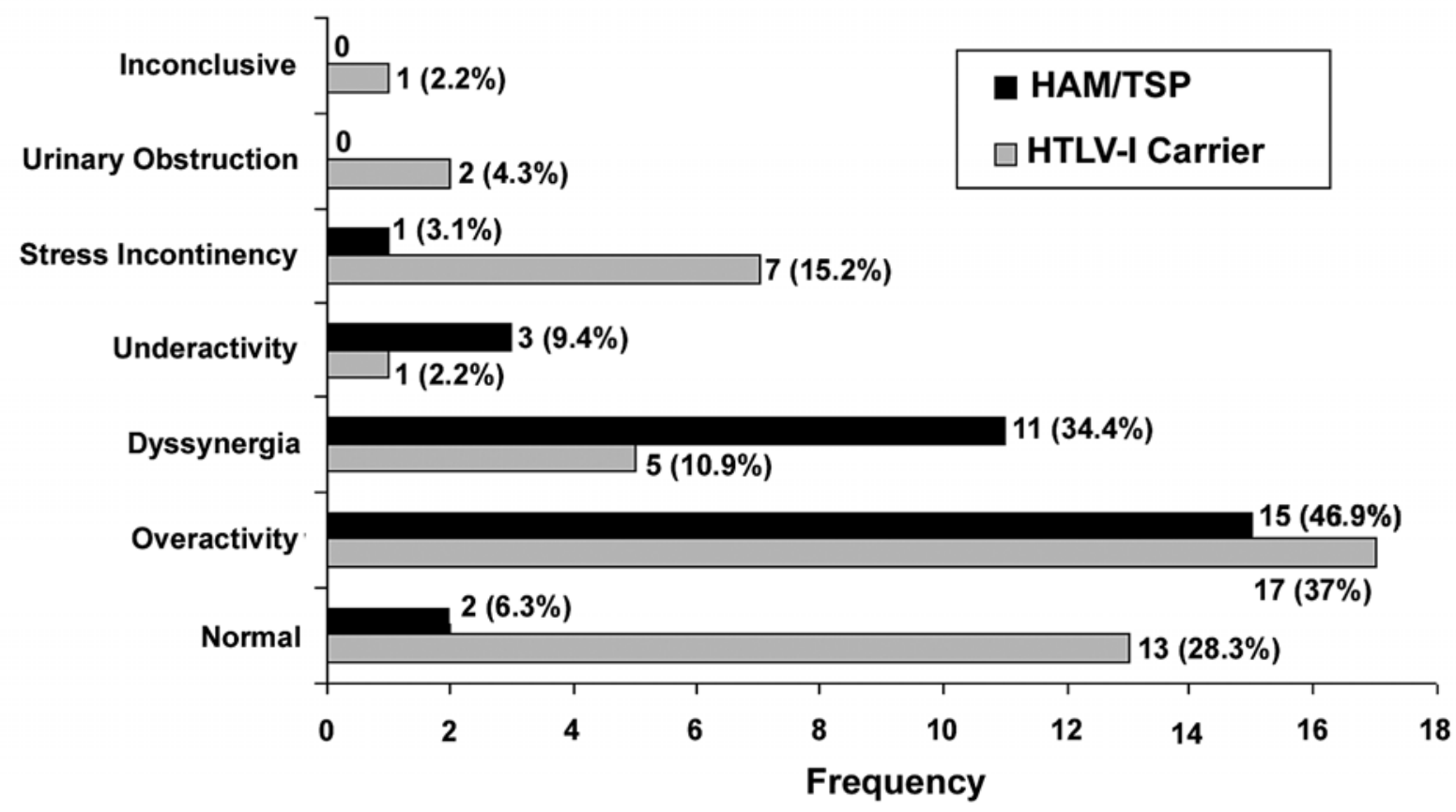

Figure 1 - Urodynamic findings in 78 HTLV-I infected individuals according to Expanded Disability Status Scale (EDSS) classification; HTLV-I-Associated Myelopathy/Tropical Spastic Paraparesis (HAM/TSP); $n=32$ and HTLV-I carrier; $n=46$. 
Table 2 - Frequency of urinary symptoms and quality of life evaluation in HTLV-I infected individuals presenting either detrusor overactivity $(D O)$ or detrusor-external sphincter dyssynergia (DESD) on urodynamic evaluation.

\begin{tabular}{|c|c|c|c|c|}
\hline Variables & $\begin{array}{c}\text { DO } \\
\mathbf{n}-\% \\
{[\mathbf{N}]}\end{array}$ & $\begin{array}{c}\text { DESD } \\
\mathbf{n}-\% \\
{[\mathbf{N}]}\end{array}$ & $\mathbf{R P}$ & CI $95 \%$ \\
\hline Urinary loss & $\begin{array}{c}15-45.5 \% \\
{[33]}\end{array}$ & $\begin{array}{c}7-38.9 \% \\
{[18]}\end{array}$ & 1.16 & $0.62-2.43$ \\
\hline Urgency & $\begin{array}{c}27-81.8 \% \\
{[33]}\end{array}$ & $\begin{array}{c}17-89.5 \% \\
{[19]}\end{array}$ & 0.91 & $0.72-1.22$ \\
\hline Frequency \# & $\begin{array}{c}16-34.8 \% \\
{[46]}\end{array}$ & $\begin{array}{c}22-73.3 \% \\
{[30]}\end{array}$ & 0.47 & $0.30-0.74$ \\
\hline Dysuria & $\begin{array}{c}9-27.3 \% \\
{[33]}\end{array}$ & $\begin{array}{c}10-55.6 \% \\
{[18]}\end{array}$ & 0.49 & $0.25-0.99$ \\
\hline Quality of life* & $\begin{array}{c}26-78.8 \% \\
{[33]}\end{array}$ & $\begin{array}{c}16-94.1 \% \\
{[17]}\end{array}$ & 0.84 & $0.65-1.11$ \\
\hline
\end{tabular}

$D O=$ detrusor overactivity; $D E S D=$ detrusor-external sphincter dyssynergia; $n=$ number of cases; $N=$ total of patients; $\#=$ was defined as $<8$ and $\geq 8$ micturitions a day; $*=$ was defined as bad $/$ very bad or normal / comfortable.

$(19,20)$. Therefore, the significant presence of detrusor overactivity in patients with HAM/TSP, as compared to HTLV-I carriers, could be expected due to the physiopathology of the disease and the characteristics of the presented urinary symptoms.

Detrusor overactivity was the most frequent urodynamic alteration and may be responsible for the urological symptomatology observed in the studied HTLV-I infected population. Detrusor overactivity is responsible for irritative bladder symptoms (dysuria, nocturia, urgency, frequency and possibly, urge incontinence); whereas DESD is a suitable explanation for the obstructive symptoms, during the bladder emptying phase (abdominal straining and sensations of incomplete bladder emptying). In our study DO was present in $41 \%$ of HTLV-I infected individuals and was statistically associated to the occurrence of nocturia, urgency, and frequency. Detrusor-external sphincter dyssynergia, observed in 20.5\% of HTLV-I infected subjects (15 individuals: 4 HTLV-I carriers and $11 \mathrm{HAM}$ /TSP patients), was statistically associated to HAM/TSP. Previous survey of five individuals with HAM/TSP reported DESD in $80 \%$ of cases (21). Another work from Japan described DESD in $65 \%$ in a series of $26 \mathrm{HAM}$ /TSP patients with voiding dysfunction (22).
Of the 46 HTLV-I carriers, $39.1 \%$ had detrusor overactivity without DESD, suggesting that the disruption of the pontine reflex pathways is commonly involved, at a subclinical level, quite early in the demyelinating process. In the present study, four patients without HAM/TSP presented DESD of mild degree. These subjects, besides the symptoms of overactive bladder, also presented hesitancy, interrupted urinary flow, and sensation of incomplete bladder emptying. Despite the well-documented involvement of the upper urinary tract in individuals with DESD, our evaluation through complementary exams (urinary tract ultrasonography, urinalysis, urine culture, and renal function tests) did not identify any abnormality. Detrusor-external sphincter dyssynergia of mild degree indicates that these patients present an initial stage of a progressive chronic disease with great risk of further compromise the upper urinary tract.

One test was considered inconclusive. It was performed in an independent facility with incomplete analysis and limited quality. The patient was referred to a second urodynamic evaluation. One HTLV-I carrier presented an obstructive pattern (a 61 year old male with benign prostate enlargement). Four patients were found to have detrusor hy pocontractility. This pattern is compatible with infrasacral lesions, 
caused by conditions such as MS and other myelitis (23).

Quality of life evaluation as assessed by QOL questionnaire showed that the individuals who presented either DO or DESD were not satisfied with their present urinary condition. The majority of HTLVI infected individuals with voiding dysfunction presented a negative impact on QOL, even more severe in those with HAM/TSP (13.9\% carriers and $81 \%$ in HAM/TSP; OD 26.3).

\section{CONCLUSIONS}

HTLV-I infection is related to myelopathy associated with important urological manifestations. The exact characterization of the dysfunction and the therapeutic plan should be individualized by the urodynamic evaluation. Detrusor overactivity was the most frequent urodynamic finding in the studied sample and, probably, the main cause of urinary symptoms. The increased frequency of detrusor overactivity without DESD among the HTLV-I carriers suggested that the disruption of the pontine reflex pathways is commonly involved at a subclinical level, quite early in the demyelinating process. Health-care professionals, especially urologists, need to be familiarized with that pathology which incidence has been increasing.

\section{ACKNOWLEDGEMENT}

This work was supported by the Brazilian National Research Council (CNPq) and Bahia Foundation for Research Support (FAPESB).

\section{CONFLICT OF INTEREST}

None declared.

\section{REFERENCES}

1. Chung HK, Young HA, Goon PK, Heidecker G, Princler GL, Shimozato O, et al.: Activation of interleukin-13 expression in T cells from HTLV-I -infected individuals and in chronically infected cell lines. Blood. 2003; 102: 4130-6.

2. Galvao-Castro B, Loures L, Rodriques LG, Sereno A, Ferreira Junior OC, Franco LG, et al.: Distribution of human T-lymphotropic virus type I among blood donors: a nationwide Brazilian study. Transfusion. 1997; 37:242-3.

3. Gessain A, Barin F, Vernant JC, Gout O, Maurs L, Calender A, et al:: Antibodies to human T-lymphotropic virus type-I in patients with tropical spastic paraparesis. Lancet. 1985; 2: 407-10.

4. Osame M, Usuku K, Izumo S, Ijichi N, Amitani H, Igata A, et al.: HTLV-I associated myelopathy, a new clinical entity. Lancet. 1986; 1: 1031-2.

5. Araujo A de Q, Alfonso CR, Schor D, Leite AC, de Andrada-Serpa MJ: Clinical and demographic features of HTLV-I associated myelopathy/tropical spastic paraparesis (HAM/TSP) in Rio de Janeiro, Brazil. Acta Neurol Scand. 1993; 88: 59-62.

6. Araujo A de Q: T-linfotrópico humano (HTLV-I) Aspectos históricos. Rev Bras Neurol. 1992; 28: 40-6.

7. Castro N, Oliveira P, Freitas D, Rodrigues W, Muniz A, Carvalho E: Erectile dysfunction and HTLV-I infection: a silent problem. Int J Impot Res. 2005; 17: 364-9.

8. De Castro-Costa CM: Tropical spastic paraparesis: a necessary redefinition. Arq Neuropsiquiatr. 1996; 54: 131-5.

9. Namima T, Sohma F, Imabayashi K, Nishimura Y, Orikasa S: Two cases of neurogenic bladder due to HTLV-I associated myelopathy (HAM). Nippon Hinyokika Gakkai Zasshi. 1990; 81: 475-8.

10. Hattori T, Sakakibara R, Yamanishi T, Yasuda K, Hirayama K: Micturitional disturbance in human Tlymphotropic virus type-1-associated myelopathy. J Spinal Disord. 1994; 7: 255-8.

11. Kurtzke JF: Rating neurologic impairment in multiple sclerosis: an expanded disability status scale (EDSS). Neurology. 1983; 33: 1444-52.

12. Castro NM, Freitas DM, Rodrigues Jr W, Muniz A, Oliveira P, Carvalho EM: Neurogenic bladder as the first manifestation of HTLV-I infection. DST J Bras Doenças Sex Transm. 2002; 14: 32-4.

13. Norris JP, Staskin DR: History, physical examination, and classification of neurogenic voiding dysfunction. Urol Clin North Am. 1996; 23: 337-43.

14. Stoller LM, Presti JC, Carrol PR. Urinary Incontinence. In: McPhee SJ, (ed.), Current Medical Diagnosis \& Treatment. San Francisco. McGraw-Hill. 2001: 943-6. 
15. Harvey MA, Kristjansson B, Griffith D, Versi E: The Incontinence Impact Questionnaire and the Urogenital Distress Inventory: a revisit of their validity in women without a urodynamic diagnosis. Am J Obstet Gynecol. 2001; 185:25-31.

16. Amarenco G, Marquis P, McCarthy C, Richard F: Quality of life of women with stress urinary incontinence with or without pollakiuria. Presse Med. 1998; 27: 5-10.

17. Blaivas JG: Issues of uroselectivity in male and female LUTS. Summary of the meeting. BJU Int. 2000; 86 Suppl 2:55.

18. Aye MM, Matsuoka E, Moritoyo T, Umehara F, Suehara M, Hokezu Y, et al.: Histopathological analysis of four autopsy cases of HTLV-I-associated myelopathy/ tropical spastic paraparesis: inflammatory changes occur simultaneously in the entire central nervous system. Acta Neuropathol (Berl). 2000; 100: 245-52.

19. Lima CLM, Rabolini G, Menna-Barreto M, dos Santos $\mathrm{EB}$, Koff WJ: Urodynamic alterations in patients with HTLV-I infection. Int Braz J Urol. 2002; 28: 452-7.

20. Saito M, Kato K, Kondo A, Miyake K: Neurogenic bladder in HAM (HTLV-I associated myelopathy). Hinyokika Kiyo. 1991; 37: 1005-8.

21. Walton GW, Kaplan SA: Urinary dysfunction in tropical spastic paraparesis: preliminary urodynamic survey. J Urol. 1993; 150: 930-2.

22. Yamashita H, Kumazawa J: Voiding dysfunction: patients with human T-lymphotropic-virus-type-1associated myelopathy. Urol Int. 1991; 47 Suppl 1: 6971.

23. Araki I, Matsui M, Ozawa K, Takeda M, Kuno S: Relationship of bladder dysfunction to lesion site in multiple sclerosis. J Urol. 2003; 169: 1384-7.

Accepted after revision:

January 8, 2007

\author{
Correspondence address: \\ Dr. Néviton Matos de Castro \\ Rua da Graça, 345 / 1402 \\ Salvador, BA, 40120-411, Brazil \\ Fax: + 55 71 336-3421 \\ E-mail: neviton_castro@uol.com.br
}

\title{
EDITORIAL COMMENT
}

Etiopathogenia of tropical spastic paraparesis has not been totally established. Apparently viral and autoimmune toxic factors are involved leading us to believe in a multifactor disease (1). A deeper knowledge about infection by HTLV-I, that endemically attacks people form many regions of the world is of utmost importance not only on the urological but also on the public health point of view. It is an infection with an occurrence in a broad age range, and direct repercussion in the socioeconomic level, especially when it attacks working-age adults.
The present study demonstrated the important correlation between the severity of the disease and the degree of vesicosphincteric compromise. It is even more relevant the determination of an evolution pattern in the micturition compromise of the individuals carrying this infection. Up to the present moment the attempts to specifically treat myelopathy associated to HTLV-Iwere frustrated, with some antivirals and immunomodulators still being investigated (2). The urodynamic evidence of detrusor hyperactivity in HTLV-I seropositive individuals, still without clinical 
neurological evidence, can allow this people the possibility of a therapeutic intervention that might halt the inexorable evolution of this disease. The followup of those patients with an initial manifestation of vesicosphincteric dysfunction is critical in the determination of the possible efficacy of a precocious therapeutic intervention.

\section{REFERENCES}

1. Zaninovic' V: Possible etiologies for tropical spastic paraparesis and human $\mathrm{T}$ lymphotropic virus Iassociated myelopathy. Braz J Med Biol Res. 2004; 37: 1-12.

2. Ribas JG, Melo GC: Human T-cell lymphotropic virus type 1(HTLV-I )-associated myelopathy. Rev Soc Bras Med Trop. 2002; 35: 377-84.

Dr. José Carlos Truzzi Section of Urology Santo Amaro University, UNISA São Paulo, Brasil E-mail: jctruzzi@hotmail.com

From this study, I may suggest that central nervous system infected patients in association with urinary symptoms should have urodynamic evaluation for early diagnosis and treatment of lower urinary tract dysfunction.

Dr. Yao-Chi Chuang Dept. of Urology, Chang Gung Memorial Hospital Chang Gung University College of Medicine Kaohsiung, Taiwan E-mail: chuang82@ms26.hinet.net 